\section{O Poder do Capital Psicológico: A Força das Crenças no Comportamento Empreendedor}

\author{
The Power of Psychological Capital: The Strength of Beliefs in Entrepreneurial \\ Behavior
}

Luciano Gonçalves de Lima'
Vânia Maria Jorge Nassif
Marcia Maria Garçon

\section{RESUMO}

Objetivo: esta pesquisa teve por objetivo analisar o comportamento empreendedor a partir dos componentes do capital psicológico e da teoria social cognitiva, na perspectiva da agência humana. Métodos: foi empregada a pesquisa qualitativa, com entrevistas em profundidade, com 21 empreendedores de diferentes perfis. As falas foram interpretadas pela análise de conteúdo e confrontadas com as teorias. Resultados: os resultados evidenciam que as ações desenvolvidas pelos entrevistados no decorrer da criação e desenvolvimento do negócio estão alinhadas às características empreendedoras conforme a literatura, sem distinção de gênero, idade ou tempo de atuação. Esses indivíduos expressam suas crenças em comportamentos de autoeficácia, otimismo, esperança, resiliência, intencionalidade, antecipação, autorreatividade e autorreflexão como mecanismos de enfrentamento de desafios e aproveitamento de oportunidades. Conclusões: esses achados indicam que as forças psicológicas atuam como elementos fundamentais e de extrema importância para o sucesso do empreendedor, tendo que ser compreendidas no âmbito teórico e gerencial como um elemento de relevância às pesquisas.

Palavras-chave: comportamento empreendedor; capital psicológico; teoria social cognitiva; agência humana.

Classificação JEL: L26, D91, M10.

'Universidade Nove de Julho, Programa de Pós-Graduação em Administração, São Paulo, SP, Brasil.

\section{ABSTRACT}

Objective: this research aimed to analyze entrepreneurial behavior from the components of psychological capital and cognitive social theory, from the human agency perspective. Methods: we used qualitative research along with in-depth interviews, conducted with 21 entrepreneurs with different profiles. The speeches were interpreted by content analysis and expanded into theories. Results: the results show that the actions developed by the interviewees during the creation and development businesses are aligned with the entrepreneurial characteristics, according to the literature, without distinction of gender, age or length of experience. As coping mechanisms for challenges and opportunities, these individuals express their beliefs in behaviors of self-efficacy, optimism, hope, resilience, intentionality, anticipation, self-actualization, and self-reflection. Conclusions: these findings indicate that the psychological forces act as fundamental elements for the success of the entrepreneur, which is essential to being understood in the theoretical and managerial scope and as a relevant element to the research.

Keywords: entrepreneurial behavior; psychological capital; cognitive social theory; human agency.

Como citar: Lima, L. G. de, Nassif, V. M. J., \& Garçon, M. M. (2020). The power of psychological capital: The strength of beliefs in entrepreneurial behavior. Revista de Administração Contemporânea, 24(4), 317-334. https://doi.org/10.1590/1982-7849rac2020180226

Editor-chefe: Wesley Mendes-Da-Silva (Fundação Getulio Vargas, EAESP, Brasil) Parecerista s: Liliane Guimarães (PUC-Minas, Programa de Pós-graduação em Administração, Brasil) (li) Luiza Martins (PUC-Rio, Brasil)

Recebido em: $24 / 08 / 2018$ Última versão recebida em: 14/06/2019 Aceite em: $27 / 07 / 2019$

\begin{tabular}{|c|c|c|c|c|c|c|c|c|c|}
\hline & 1 & 2 & 3 & 4 & 5 & 6 & 7 & 8 & 9 \\
\hline $1^{a}$ rodada & 2 & $\stackrel{8}{2}$ & & & & & & & \\
\hline $2^{a}$ rodada & (x) & $\stackrel{9}{2}$ & & & & & & & \\
\hline $3^{a}$ rodada & 8 & & & & & & & & \\
\hline
\end{tabular}




\section{INTRODUÇÃO}

A área de empreendedorismo vem sendo estudada de maneira fragmentada, dificultando a consensualidade quando o assunto se refere ao comportamento empreendedor. Dentro do campo da psicologia, McClelland (1965) foi um dos precursores ao considerar a Necessidade de Realização (Nach) como a característica mais distintiva da motivação para empreender. McClelland (1961) argumenta que as pessoas com Nach maior, provavelmente, procuram atividades empreendedoras atuando em outros tipos de papéis. Shane e Venkataraman (2000) afirmam que a percepção de oportunidades de negócios é um dos meios para descobrir, criar, avaliar e explorar produtos e serviços futuros, não atribuindo apenas às motivações influências para empreender.

Outra variável que compõe o elo do presente estudo no contexto cognitivo é o capital psicológico (PsyCap). Oriundo da psicologia positiva, tem suas bases estabelecidas por quatro dimensões: autoeficácia, otimismo, esperança e resiliência. Para o campo, elas produzem um estado de acréscimo psicológico positivo como confiança, responsável pelo ânimo a realizar esforços necessários para ser bem sucedido em tarefas desafiantes, por manifestar perseverança em relação aos objetivos definidos, por redirecionar os meios para atingir os fins e revelar capacidades para recuperar-se das adversidades (Luthans, Youssef, \& Avolio, 2007; Luthans \& Youssef, 2004).

Na perspectiva da agência humana, a teoria social cognitiva desempenha um importante papel na capacidade das pessoas se autorregularem, codificar informações e executar comportamentos (Bandura, 1986). Esse autor pontua que a autoeficácia, pilar da teoria social cognitiva, é relevante para a compreensão do comportamento humano, e que os resultados produzidos por suas ações são decorrentes de suas crenças, o que as levam a fazer as coisas acontecerem (Bandura, $1977 ;$ 1986). Essencial para esse conceito de agência é o entendimento de que, entre outros fatores pessoais, as crenças exercem certo grau de controle sobre os pensamentos, sentimentos e ações. O autor afirma que "aquilo que as pessoas pensam, creem e sentem afeta a maneira como se comportam" (Bandura, 1986, p. 25).

Estudos que relacionam, conjuntamente, a área do empreendedorismo com o capital psicológico e a agência humana não são evidenciados na literatura pesquisada, tanto nacional como internacional, sobretudo, quando a busca é pela compreensão do comportamento empreendedor. Conforme já apontaram Lima e Nassif (2017b), alguns trabalhos apresentam esses construtos de forma fragmentada e dissociada ao objeto da pesquisa, por isso, é possível afirmar que existe uma lacuna nas pesquisas: não há estudos que integram o capital psicológico e a agência humana na explicação do comportamento empreendedor. Não obstante a ausência de estudos integrados, Lazarus e Folkman (1994) afirmam que há estressores que produzem diferentes reações nas pessoas e, por consequência, diferentes comportamentos.

É precisamente essa a lacuna que este estudo visa eliminar e trazer contribuições para o avanço do conhecimento na área.

A capacidade de identificar e aproveitar oportunidades e criar e gerenciar empresas em um contexto em constantes mudanças e competitividade têm exigido cada vez mais características peculiares dos atores que estão à frente de seus empreendimentos. As ações e tomadas de decisões que os indivíduos enfrentam, constantemente, nas suas trajetórias empreendedoras são complexas e desafiadoras, suscitando uma inquietação em melhor compreender a questão de pesquisa que orienta este artigo: como o comportamento empreendedor pode ser explicado a partir do construto do capital psicológico e da teoria social cognitiva, na perspectiva da agência humana?

Assim, identificar capacidades positivas psicológicas (PsyCap) nos indivíduos empreendedores pode auxiliar no entendimento e ampliação do campo de estudo em empreendedorismo, por serem estas capacidades positivas, passíveis de desenvolvimento.

Este estudo também busca contribuir ao apontar que as características comportamentais influenciadas pelas forças psicológicas não se modificam pelo gênero, idade ou tempo de atuação. Os empreendedores entrevistados apresentam diferentes perfis: jovens iniciando seus empreendimentos, mulheres com empreendimentos em diferentes fases e empreendedores experientes e que estão em cargos de comando na associação.

\section{FUNDAMENTAÇÃO TEÓRICA}

\section{Comportamento empreendedor: aspectos conceituais}

O corpo de conhecimento sobre o comportamento empreendedor avança nos estudos empíricos que buscam explicar, prever e controlar o comportamento de indivíduos envolvidos na descoberta e exploração de oportunidades e criação e desenvolvimento de novas organizações de risco 
(Kuratko, Ireland, Covin, \& Hornsby, 2005; Smith, Di Gregorio \& Anderson, 2002). São as circunstâncias contextuais, aspectos socioeconômicos e culturais e atividades desenvolvidas pelos empreendedores que melhor explicam a abrangência e a variabilidade de seus comportamentos (Lévesque \& Minniti, 2006). Há ainda estudos que abordam as atividades institucionais e a maneira como as pessoas se comportam e se adequam a elas para explicar o comportamento empreendedor (Welter \& Smallbone, 2011).
Como um construto de pesquisa, o comportamento empreendedor é o resultado imbricado de cognições e emoções dos atores empreendedores. A abordagem psicológica, defendida por McClelland (1962), cria um núcleo comum de traços de personalidade desses sujeitos. A literatura apresenta uma extensa lista dessas características. A Figura 1 apresenta um quadro sumário com alguns dos autores representativos dessa abordagem.

\begin{tabular}{|c|c|}
\hline Traços de personalidade & Autores \\
\hline Organizado, líder, formador de equipe, bem relacionado. & Kirzner (1973) \\
\hline Visionário, saber tomar decisões. & Baron e Shane (2011) \\
\hline $\begin{array}{l}\text { Necessidade de realização, o lócus de controle interno e a } \\
\text { propensão ao risco são atributos que contribuem para o sucesso } \\
\text { de novos negócios. }\end{array}$ & Brockhaus (1982) \\
\hline $\begin{array}{l}\text { Empreendedores com lócus de controle interno buscam alta } \\
\text { conquista. }\end{array}$ & Brockhaus e Horwitz (1986) \\
\hline Independente; construtor de seu destino. & Bruyat e Julien (2001); Bygrave e Hofer (1991) \\
\hline Determinado, dinâmico, dedicado, otimista e apaixonado. & $\begin{array}{l}\text { Brancher, Oliveira e Roncon (2012); Brush, Carter, Greene, Hart } \\
\text { e Gatewood (2002); Julien (2010) }\end{array}$ \\
\hline Autoconfiança e motivação pessoal & Honma (2007) \\
\hline Espírito criativo e de pesquisador. & Kirzner (2009); Mehrabi e Kolabi (2012) \\
\hline Acreditar nas suas habilidades empreendedoras. & Bullough, Renko e Myatt, (2014) \\
\hline Dedicação, motivação, respeito, responsabilidade. & Envick (2014) \\
\hline $\begin{array}{l}\text { Vontade de ter um negócio próprio, desejo de ter controle sobre } \\
\text { o seu tempo, interesse pela atividade. }\end{array}$ & Bernardino, Santos e Cardoso (2018) \\
\hline $\begin{array}{l}\text { São autogestores que se encarregam de realizar tarefas que } \\
\text { vão desde a solução de um problema técnico à tomada de } \\
\text { decisões. a liberdade e autonomia em planejar e organizar o } \\
\text { trabalho permite ressignificar as vivências transformando-as em } \\
\text { vivências de prazer. }\end{array}$ & Guimarães (2019) \\
\hline
\end{tabular}

Figura 1. Quadro sumário: principais fontes da literatura.

Fonte: Elaborado pelos autores.

Alguns autores também apontam a importância de um conjunto de habilidades, conhecimentos e experiências para o sucesso dos empreendedores. Filion (1999) indica a criatividade, persistência, internalidade; Armond e Nassif (2009) tratam o comportamento da liderança do empreendedor e Bhidé (2004) valoriza o conhecimento, capacidade de planejamento e disposição em assumir riscos calculados e criar valor para a sociedade. Shane e Venkataraman (2000) dizem que os empreendedores exploram oportunidades.

O empreendedor é, então, aquele que percebe e age sobre uma oportunidade desconhecida, sendo capaz de combinar os meios produtivos para propiciar o desenvolvimento econômico (Almeida, Valadares, \& Sediyama, 2017). Para isso, identificam dificuldades e incertezas, processam os elementos do contexto e tomam decisões em função do desempenho empresarial (Wood, Williams \& Drover, 2017).

Esses aspectos corroboram o estudo de Nassif, Hashimoto e Amaral (2014) ao encontrarem perfil de estrategistas nas características do comportamento empreendedor, que apresentaram conhecimentos sobre produto, mercado, cliente e liderança na gestão de pessoas.

As características comportamentais encontradas pelos autores podem ser sumarizadas na Figura 2. 


\begin{tabular}{|c|c|}
\hline Características Comportamentais & Autores \\
\hline Criatividade, persistência, internalidade, liderança. & Filion (2009) \\
\hline Liderança. & Armond e Nassif (2009) \\
\hline $\begin{array}{c}\text { Conhecimento, capacidade de planejamento, tomada de riscos, } \\
\text { criação de valor para a sociedade. }\end{array}$ & Bhidé (2004) \\
\hline Explorar oportunidades. & Shane e Venkataraman (2000) \\
\hline $\begin{array}{c}\text { Capacidade de combinar os meios produtivos para propiciar o } \\
\text { desenvolvimento econômico. }\end{array}$ & Almeida, Valadares e Sediyama (2017) \\
\hline $\begin{array}{l}\text { Capacidade de avaliar dificuldades e incertezas, processar } \\
\text { os elementos do contexto e tomar decisões em função do } \\
\text { desempenho empresarial. }\end{array}$ & Wood, Williams e Drover (2017) \\
\hline $\begin{array}{c}\text { Estrategistas: conhecimento de mercado, produto, clientes e } \\
\text { funcionários. }\end{array}$ & Nassif, Hashimoto e Amaral (2014) \\
\hline
\end{tabular}

Figura 2. Quadro sumário: características comportamentais.

Fonte: Elaborado pelos autores.

Inseridos na abordagem psicológica, Bandura, Azzi e Polydoro (2008) alertaram que o mundo contemporâneo está apresentando novas posturas psicológicas dos empreendedores. E as crenças se apresentam como importantes no desempenho das tarefas de empreender (Urban, 2012). Neste cenário, torna-se imprescindível entender a agência humana como um campo de estudos.

Assim, buscando ampliar o conhecimento acerca da necessidade de novas posturas psicológicas que são expressas pelo comportamento empreendedor, o próximo tópico aborda a origem e as dimensões do capital psicológico.

Vale ressaltar que a pesquisa científica, nacional e internacional, acerca do comportamento empreendedor explicado à luz dos componentes do construto do capital psicológico e da teoria social cognitiva, na perspectiva da agência humana, apresenta uma literatura ainda incipiente, quando pesquisadas conjuntamente.

\section{Capital psicológico dimensões}

A abordagem psicológica nos indica que empreendedores obtém sucesso em seus empreendimentos devido ao seu alto grau de resistência mental para decidir e tomar decisões estratégicas. Lazarus (1991) afirma que os afetos são provocados e expressos em eventos diários e Damásio (1995) explica que as emoções são indispensáveis na vida racionais. Ao que tudo indica são esses aspectos que diferenciam o comportamento dos indivíduos. Csikszentmihalyi (2004) conceitua resistência mental como os recursos psíquicos que podem ser extraídos a fim de enfrentar os desafios emocionais do momento.

Neste sentido, o Capital Psicológico tornase um alicerce para discutir o comportamento empreendedor. Os autores seminais (Luthans, Youssef, \& Avolio, 2007; Luthans \& Youssef, 2004), indicaram que o capital psicológico traz parâmetros relacionados à pessoa do empreendedor: quem ele é, como se comporta e reage frente às adversidades em termos emocionais e comportamentais; e às suas competências: autoeficácia, otimismo, esperança e resiliência. A afetividade tem um sentido pleno: está relacionada às vivências e motivações das pessoas. E o cognitivo organiza o pensamento, ajuda a resolver problemas e buscar soluções.

O capital psicológico positivo ou simplesmente capital psicológico (PsyCap) produz um estado de acréscimo psicológico em que a pessoa apresenta uma elevada confiança para despender o esforço necessário para ser bem-sucedida em tarefas desafiantes. Faz atribuições positivas acerca dos acontecimentos que vão suceder no presente e no futuro, manifesta perseverança em relação aos objetivos definidos, e, quando necessário, mostra-se capaz de redirecionar os meios para atingir os fins. Revela ainda a capacidade para a recuperação das adversidades (Luthans, Youssef, \& Avolio, 2007; Luthans \& Youssef, 2004). A Figura 3 ilustra os quatro fatores que formam esse construto. 


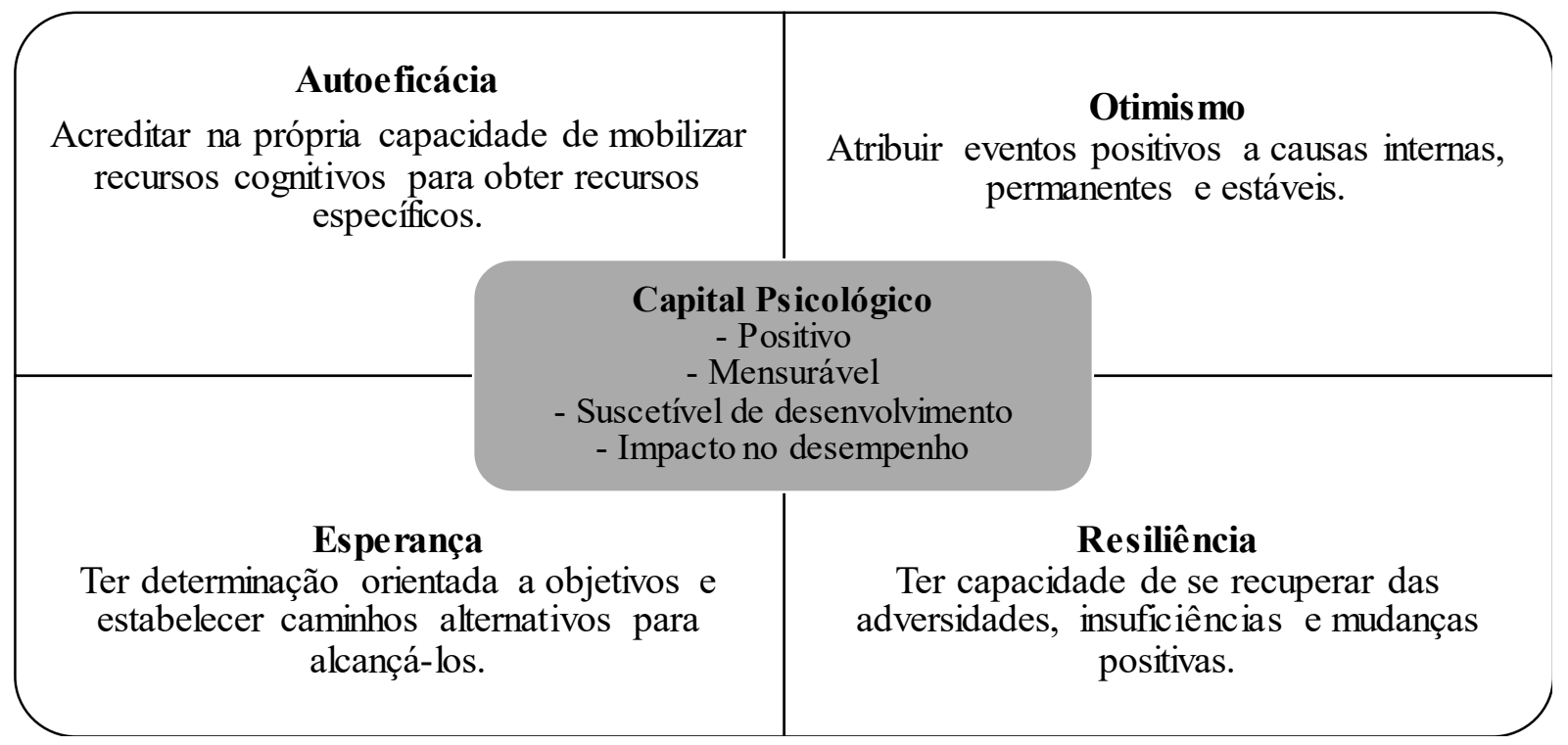

Figura 3. Dimensões do capital psicológico positivo.

Fonte: Adaptada de Page, L. F., \& Donohue, R. (2004). Positive psychological capital: A preliminary exploration of the construct [Working Paper 51/04]. Monash University, Business and Economics, Melbourne, Australia.

Argumentos apresentados por Luthans (2002) dizem que os recursos psicológicos dos indivíduos são pontos referenciais para serem investidos e desenvolvidos até atingirem seu pleno potencial.

Luthans e Youssef (2004) sugerem que a combinação de autoeficácia, otimismo, esperança e resiliência que formam o construto do Capital Psicológico, atuam em sinergia para construir capital psicológico dentro dos indivíduos. Assim, o capital psicológico é positivo, suscetível de desenvolvimento, tem impacto no desempenho e, principalmente, pode ser mensurado.

Alguns autores abordam as variáveis do capital psicológico individualmente. Amorim, Rodrigues, Stewart, Xiao e Snyder (2018), por exemplo, mensuraram a autoeficácia em professores em um estudo de comparação de duas escalas um instrumento específico para medir o público professor x uma escala geral. E confirmaram que essa dimensão é preditiva para o comportamento empreendedor desse público. Muitos outros estudos atestaram que a autoeficácia é variável psicológica com maior poder preditivo sobre a intenção de criar um negócio (Boyd \& Vozikis, 1994; Bygrave \& Zacharakis, 2010; Liñán \& Chen, 2009; Pihie, 2009; Scheier \& Carver, 2003).

O otimismo tem sido estudado como fator para a tomada de decisões de investimentos e em relação com a confiança. Fourati e Attitalah (2018) descobriram que o empreendedor otimista prefere a equidade nas finanças e opta pelo equilíbrio entre dívidas e empréstimos. Já Dai, Ivanov e Cole (2017) descobriram que o otimismo é uma característica positiva ao empreendedor que busca por investimentos por não prejudicar, de forma alguma, a obtenção de empréstimos.

Também há estudos que associam as variáveis individuais do capital psicológico com outros construtos. Giacomin, Janssen e Shinnar (2015) avaliaram o otimismo em estudantes e perceberam a sua relação com a intenção de empreender e a confiança. Há evidências crescentes que a autoeficácia está relacionada com a criatividade, sendo capaz de alcançar resultados criativos em um ambiente de trabalho (Gong, Huang, \& Farh, 2009; Tierney \& Farmer, 2011), com comportamentos inovadores (Jiang \& Gu, 2017) e com a confiança em lidar com os desafios e incertezas inerentes ao desenvolvimento e implantação das novas ideias no local de trabalho (Richter, Hirst, Knippenberg, \& Baer, 2012).

Lima e Nassif (2017a, 2017b), ao adotarem uma abordagem integrativa, defendem que os fatores do capital psicológico atuam de forma indissociada e se constituem como um investimento emocional que suporta os empreendedores para a tomada de decisões em cenários de pressões. Para eles, a esperança e o otimismo contribuem ao enfrentamento dos desafios, a autoeficácia auxilia no desenvolvimento das estratégias e de caminhos ao sucesso e a resiliência conduz os empreendedores à superação das dificuldades. Schaefer e Minello (2017) descrevem como a mentalidade empreendedora 
estrutura o seu modo de perceber e entender a si e o mundo ao redor, definindo, por consequência, o seu modo de agir por meio da ação empreendedora.

Ao compreendê-lo dessa forma, abrem-se caminhos para o avanço das pesquisas sobre os recursos psicológicos que se potencializam na capacidade do indivíduo em atingir seu pleno potencial. Ao seguir esse propósito, faz sentido explorar a relação entre capital psicológico e a aptidão à agência humana, que será discutida no próximo tópico.

\section{Agência humana e suas características}

O princípio básico que fundamenta a Teoria Social Cognitiva (TSC) é agência humana, na qual o autodesenvolvimento e a mudança de comportamento humano são explicados. Nela, o indivíduo não é um alvo passivo das influências do meio, mas pelo contrário, age sobre ele e toma decisões conscientes das circunstâncias de sua vida. Na teoria da agência, o ser agente significa ter intencionalidade no agir.
Por isso, Bandura (2008) indica características humanas básicas como a Intencionalidade, responsável por definir estratégias e planos que significam intenção de ação; a Antecipação, relacionada com temporalidade, na qual o tempo futuro representa um guia motivacional, mola propulsora de atos prospectivos para atingimento de objetivos; a Autorregulação, que são padrões pessoais de comportamentos que monitoram e regulam seus atos e a Autorreflexão, responsável pela autoinvestigação sobre o valor e o significado de suas ações.

Portanto, é a agência humana que determina a conduta das pessoas. "As pessoas são autoorganizadas, proativas, autorreguladas, e autorreflexivas, contribuindo para as circunstâncias de suas vidas, não sendo apenas produtos dessas condições" (Bandura, 2008, p. 15). A Figura 4 a ilustra o inter-relacionamento das características da teoria da agência humana.
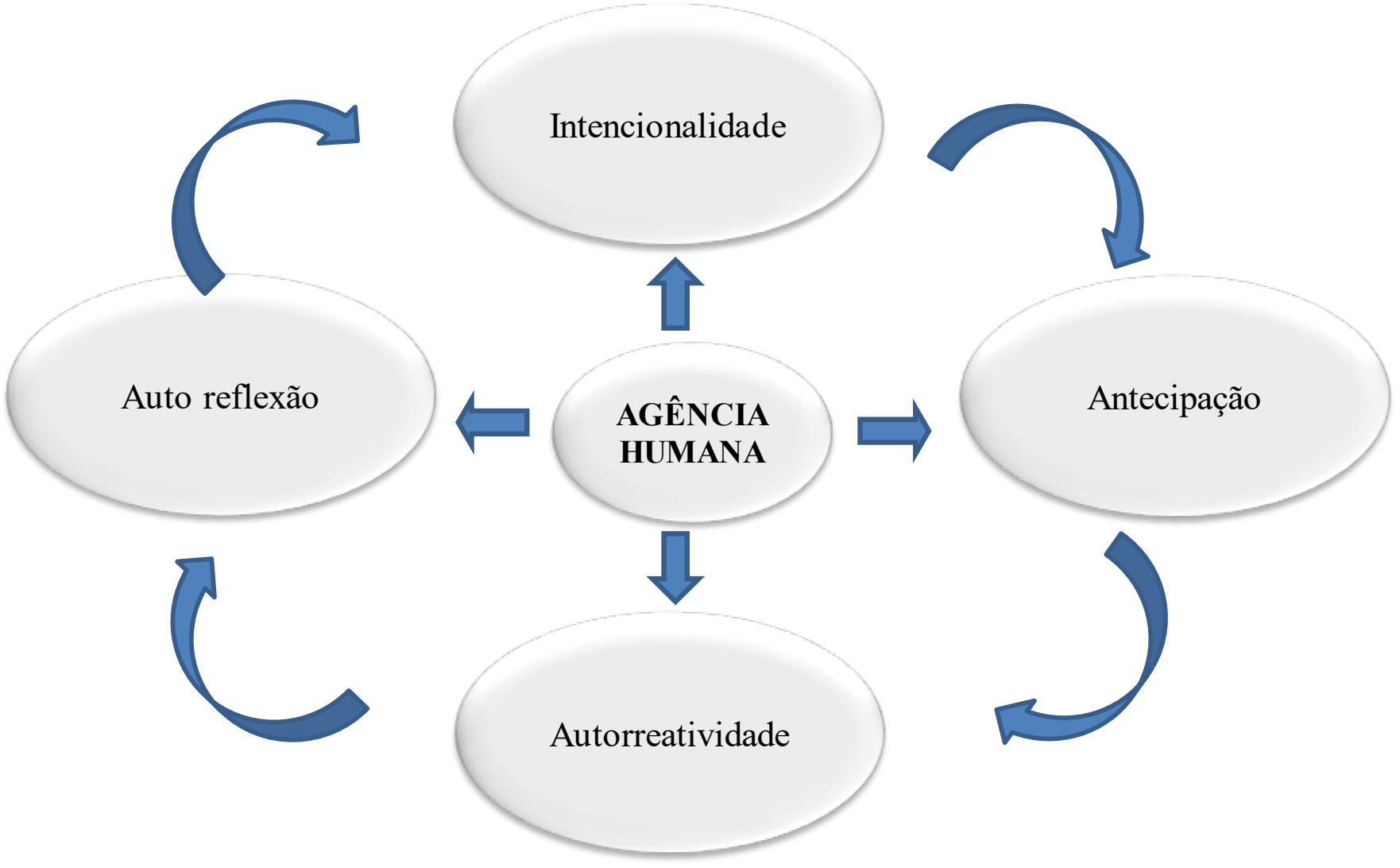

Figura 4. A agência humana e suas características.

Fonte: Elaborada pelos autores. 
Percebe-se que as características agem de forma complementar, conforme podem ser entendidas a seguir.

\section{Intencionalidade}

Intenção é a representação de um curso de ação futuro a ser adotado (Bandura, Azzi, \& Polydoro, 2008). Não se exibe como uma simples expectativa ou previsão de atos futuros, mas como um acordo proativo para a sua realização. É preciso, assim, distinguir a diferença entre a produção pessoal da ação voltada à expectativa almejada, os efeitos que desencadeiam aquele curso de ação e as consequências produzidas.

Bandura (1997) chama a atenção para a questão de que os efeitos ou resultados não são as características dos atos de agência, mas sim, a consequência. Para transformar futuros imaginados em realidade, são imprescindíveis intenções próximas ou voltadas para o presente que conduzam o indivíduo nesta direção (Bandura, 1991).

\section{Antecipação}

A expansão temporal da agência vai além do planejamento futuro. Para Bandura (1991), as pessoas instituem objetivos para si mesmos, predizem as consequências evidenciáveis de ações prospectivas, selecionam e criam cursos de ação que, possivelmente, produzirão resultados almejados e evitarão resultados prejudiciais.

Para Bandura, Azzi e Polydoro (2008), os indivíduos reorganizam suas prioridades e estruturam suas vidas à medida que avançam, e vão criando expectativas de resultados pelas relações condicionais que fazem entre episódios que ocorrem no mundo e as decorrências que determinadas ações podem causar (Bandura, 1986). Assim, há uma relação funcional entre intenção e ação, na qual eventos futuros previsíveis são transformados em motivadores e reguladores do comportamento no presente.

\section{Autorreatividade}

A agência humana não está pautada apenas em escolhas e planos de ação, mas também na capacidade de configurar cursos de ação apropriados e de motivar e regular a sua efetivação.

Assim, um agente é um autorregulador e não apenas um planejador porque ao adotar uma intenção e um plano de ação, conecta-se a pensamentos, afetos e outras ações que envolvem o monitoramento pessoal, a orientação pessoal do comportamento e as reações pessoais corretivas que o direciona ao objetivo desejado.

\section{Autorreflexão}

A autorreflexão é outra importante característica da agência humana que abrange a capacidade metacognitiva de refletir sobre si mesmo e sobre a adequação dos próprios pensamentos e ações. Assim, Bandura, Azzi e Polydoro (2008) consideram que as pessoas, além de agentes, são também conscientes do próprio comportamento.

Assim, as quatro características básicas da agência humana, conforme os atributos discutidos por Bandura (1986, 1991) e Bandura et al. (2008), funcionam como alicerce para sustentar as discussões acerca do comportamento empreendedor. O indivíduo, por conta das capacidades básicas humanas possui um sistema autorreferente que o possibilita agir intencionalmente em direção a fins específicos, elaborar planos de ação, antecipar possíveis resultados e avaliar e replanejar cursos de ação (Bandura, 1993, 2001).

A teoria social cognitiva adota também a perspectiva da agência para o autodesenvolvimento, adaptação e mudança (Bandura, 2001) entendendo que ser agente significa influenciar o próprio funcionamento $e$ as conjunturas de vida de modo propositado, induzindo pessoas a serem auto-organizadas, proativas, autorreguladas e autorreflexivas, cooperando para as circunstâncias de suas vidas.

Há que se destacar, ainda, o papel fundamental que as crenças desempenham como mecanismo de agência pessoal, no controle de pensamentos, sentimentos e ações e sobre o meio e situações vividas. "Aquilo que as pessoas pensam, creem e sentem pode afetar a maneira como se comportam", afirma Bandura (1986, p. 25). O indivíduo se torna agente e receptor de situações que produzem, ao mesmo tempo em que essas situações determinam seus pensamentos, emoções e comportamentos futuros (Bandura, 1989; Martinez \& Salanova, 2006).

O próximo tópico apresenta os procedimentos metodológicos aplicados na construção da pesquisa empírica que estudou, de maneira integrada, os construtos comportamento empreendedor, capital psicológico e teoria da agência.

\section{PROCEDIMENTOS METODOLÓGICOS}

A pesquisa amparou-se na abordagem qualitativa, que visa abordar o mundo de forma a entender, descrevere, às vezes, explicar osfenômenos sociais de maneira diferente (Flick, 2009), a partir de relatos de experiências de vida, relacionadas às biografias ou práticas cotidianas e profissionais dos sujeitos. Por isso, a abordagem qualitativa foi escolhida por atender adequadamente ao objetivo 
da pesquisa que foi analisar o comportamento empreendedor sob a ótica dos construtos do capital psicológico e da teoria social cognitiva, na perspectiva da agência humana, a partir da trajetória de um grupo de empreendedores pertencentes à Associação Comercial e Empresarial de Paranavaí (ACIAP), ao Conselho da Mulher Empresária (CME) e ao Conselho do Jovem Empresário (COJEP) da cidade de Paranavaí-PR.

Aborda também a Análise Crítica da Narrativa, que focaliza o estudo individual e enfatiza a compreensão da história de vida tal como é apresentada (Langdridge, 2007). Para a fenomenologia, a realização de uma pesquisa é sempre um questionamento sobre a maneira como as pessoas experienciam o mundo (Manen, 1990). Como na pesquisa fenomenológica a ênfase é colocada na compreensão da experiência vivida de outrem, a entrevista torna-se o procedimento mais adotado nesse tipo pesquisa.

Os contatos iniciais aconteceram em uma reunião na ACIAP, com a participação de um dos pesquisadores. O objetivo da pesquisa foi explicitado e na sequência, um convite oficializado. $\mathrm{O}$ aceite unânime dos membros da associação propiciou o agendamento das entrevistas, conforme a disponibilidade de cada participante.

Assim, nesta pesquisa foram coletadas as narrativas da trajetória de 21 empreendedores, sendo cinco homens que atuam na diretoria da Associação Comercial e Empresarial da cidade de Paranavaí (ACIAP), 11 mulheres do Conselho da Mulher Empresária (CME), e cinco jovens entre homens e mulheres do Conselho do Jovem Empresário (COJEP).

Os entrevistados foram encorajados a narrar suas trajetórias empreendedoras, guiados por um roteiro aberto, ao mesmo tempo ficando livres para discorrer sua experiência desde o processo de criação e ao longo do desenvolvimento do negócio. Todas as entrevistas foram gravadas com autorização dos participantes e transcritas. O tratamento dos dados foi feito pela categorização a priori e posteriori, que para Flores (1994), consiste em examinar as unidades de dados para encontrar os componentes temáticos que contribuem para a definição das categorias. A priori contempla o marco teórico e conceitual e a posteriori elaboramse análises indutivamente a partir dos próprios dados. Assim, a escolha da unidade de análise recai basicamente onde está localizada a informação e o fenômeno a ser pesquisado, facilitando a elaboração de um quadro com elementos que contribuem para a análise dos resultados. Tão logo as categorias ficaram definidas, as mesmas foram tratadas, qualitativamente, por meio da análise de conteúdo, sob a perspectiva de Bardin (1977).

\section{ANÁLISE E DISCUSSÃO DOS RESULTADOS}

Os resultados foram categorizados e analisados sob a perspectiva da Agência Humana, Capital Psicológico e Comportamento Empreendedor e estes geraram subcategorias com base nos elementos que formam os construtos. A Figura 5 apresenta categorias e subcategorias.
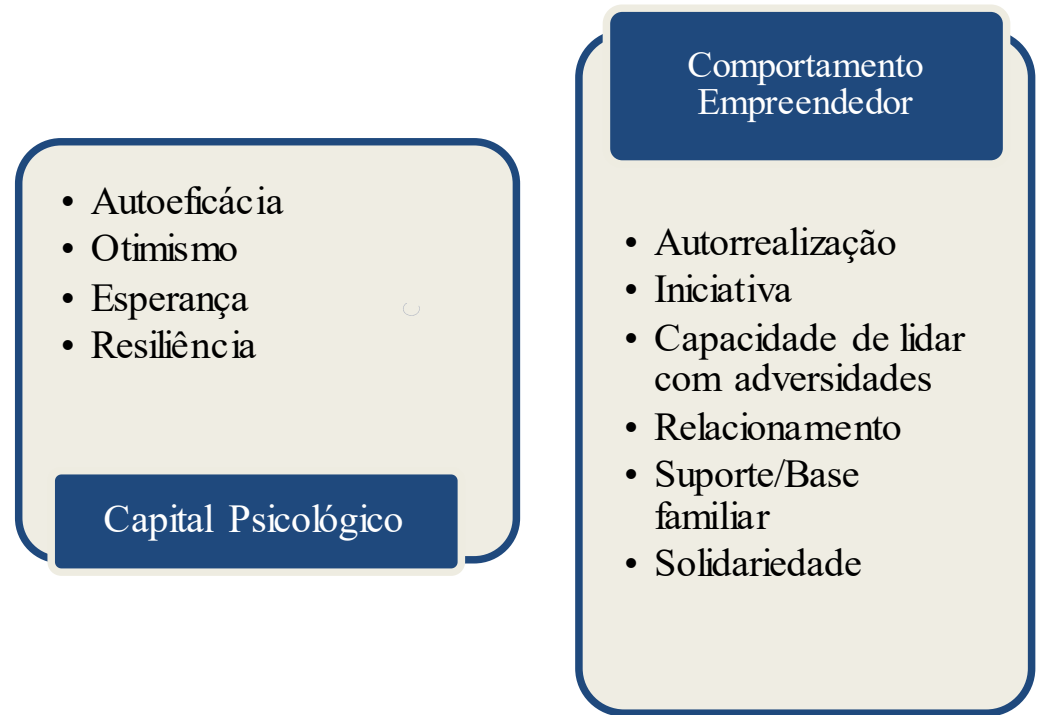

- Intencionalidade

- Antecipação

- Autorreatividade

- Autorreflexão

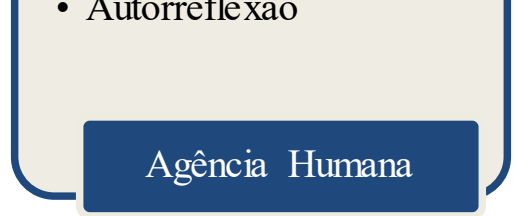

Figura 5. Categorias e subcategorias que subsidiaram a análise.

Fonte: Elaborada pelos autores. 
Visando preservar a identidade dos respondentes, doravante a indicação das ilustrações seguiram as seguintes siglas: ACIAP, para representar os diretores da Associação, CME, representando as respondentes do Conselho da Mulher Empresária e, COJEP para ilustrar as falas dos membros do Conselho dos Jovens Empresários. Todos os participantes fazem parte da Associação Comercial e Empresarial da cidade de Paranavaí (ACIAP).

Presença de agência humana no comportamento empreendedor

A análise dos depoimentos indica a presença das características de intencionalidade, antecipação, autorreatividade e autorreflexão nos comportamentos declarados desses empreendedores. Nas várias etapas de criação e desenvolvimento do negócio, a agência humana se fez presente.

\section{Intencionalidade como explicação para comportamento empreendedor}

A intencionalidade para empreender é percebida nos relatos sobre a criação do negócio. Neles, é possível identificar como os empreendedores projetaram ações futuras de acordo com um cenário de desafios que se desfraldava. A experiência relatada foi de um período de muitos desafios, e incertezas que resultaram em muita reflexão antes de tomar decisões.

“A minha intenção eu queria ser contador, eu achava bonita a profissão de contabilista e eu queria ser contabilista, mas desisti no meio do caminho e resolvi tocar os negócios que eu já estava inserido, e com o passar do tempo eu vi que o negócio era bom e tal, e tinha a chance, assim possibilidade de ser melhorado, uma vez que na época em Paranavaí nós tínhamos 7 fábricas de carrocerias, então Paranavaí foi sempre assim um polo da indústria de implementos rodoviários". (ACIAP)

"Eu vi que não tinha perfil de ser uma advogada, nem de ser uma juíza, nem promotora, não queria nada, eu queria era vender roupa, daí eu continuei, aumentei a loja, reformei, com o passar do tempo eu ia juntando dinheiro e crescendo, mas nunca com a ajuda dos meus pais, na loja não, nos estudos sim, mas na loja foi com o meu trabalho, ai depois me casei, continuei com a loja". (CME)

A intencionalidade percebida na fala dos empreendedores vem ao encontro de pesquisas anteriores que demonstraram o desejo de ter um negócio próprio e interesse pelo setor de atividade (Bernardino, Santos \& Cardoso, 2018). Também indicaram como a realidade próxima influencia o futuro imaginado por cada um para seu negócio. A intenção de empreender está relacionada com transformar futuros imaginados em realidade e, para isso, as avaliações do presente conduzem e conservam o indivíduo nesta direção (Bandura, 1991).

\section{Antecipação como explicação para o comportamento empreendedor}

Os depoimentos sobre o início dos negócios trouxeram à lembrança dos respondentes quais foram suas respostas frente ao futuro que eles imaginaram. A análise dessas falas identificou preocupação em planejar ações, com informações e dados que permitissem a tomada de decisões mais corretas à criação e desenvolvimento do negócio.

"Conversando aqui por perto, tomando café numa padaria, visualizamos o ponto fechado, e o que me chamou a atenção foi a quantidade de pessoas que passavam ali pela manhã, isso fez com que a gente ficasse tomando um café pelo período de uns 40 a 50 minutos. Eu fiz uma contagem de pessoas que passavam na calçada, e eu achei muito interessante por mais que era início de mês, que a gente sabe que tem uma predisposição de gente na praça... mesmo assim me chamou a atenção, mesmo por já ter um projeto previamente elaborado na sua cabeça... isso me deixou motivado a vir e conhecer o prédio". (COJEP)

Os relatos de outras dificuldades superadas por empreendedores participantes da pesquisa, no processo de criação e desenvolvimento do negócio, demonstram como a iniciativa e a capacidade de lidar com adversidades foram importantes no processo de ajuste e superação dos mesmos, ao se depararem com a falta de acesso à informação, gestão da equipe e gestão administrativa do negócio.

Essa relação funcional entre intenção e ação apontada na antecipação por Bandura (1986) foi demonstrada pelas atitudes desses empreendedores frente aos desafios que se apresentaram. De acordo com Kirzner (2009), Mehrabi e Kolabi (2012), essa é uma característica básica do sujeito que empreende: ter um espírito criativo e pesquisador que busca constantemente novos caminhos e soluções para situações adversas e que, por isso, tem capacidade de estabelecer e atingir objetivos guiados por sonhos realistas (Filion, 1999). Em várias situações narradas pelos entrevistados, são percebidas ações de iniciativa e capacidade para lidar com situações inesperadas. 
A característica da antecipação, assim, direciona os empreendedores a adotarem comportamentos assertivos na busca de estratégias que auxiliaram e facilitaram o alcance de seus objetivos do negócio.

A agência humana vai explicar esse comportamento pela crença que os indivíduos têm em seu poder de realização (Bandura, 2001). O capital psicológico vai se apresentar, por meio da autoeficácia empreendedora, como a correta alocação de recursos, pessoas e processos na criação e gestão de empresas competitivas (Urban, 2012).

\section{Autorreatividade como explicação para comportamento empreendedor}

Outra característica do comportamento empreendedor é a capacidade que um agente tem de ser autorregulador, ou seja, de controlar pensamentos, afetos e ações e conduzi-los a uma decisão adequada. A autorreatividade dos empreendedores é, assim, uma autorregulação da motivação, do afeto e da ação, conduzida por um conjunto de subfunções autorreferentes, que envolvem o monitoramento pessoal, a orientação pessoal do comportamento e as reações pessoais corretivas (Bandura, 1986, 1991). Nos depoimentos recolhidos, foi possível verificar que os empreendedores atuam com a estratégia de relacionamento como fruto da sua autorreatividade. Ela contribui para a criação de parcerias com clientes, funcionários, fornecedores e amigos no processo de desenvolvimento do negócio em busca de uma melhor posição competitiva da empresa, conforme a afirmação a seguir.

"O relacionamento que nós temos com o mercado fez com que nossos fornecedores, de ferragens, de móveis, de piso, acreditassem nessa ideia e financiasse esse negócio para a gente, os próprios parceiros construíram a loja para gente, financiaram para a gente com prazo". (COJEP)

A afirmação indica que, para esse setor, as parcerias são imprescindíveis na criação e no desenvolvimento do negócio.

\section{Autorreflexão como explicação para comportamento empreendedor}

Em se tratando de uma experiência autorreflexiva, que busca avaliar e alinhar pensamentos e ações, os empreendedores entrevistados demonstram uma constante autorreflexão, sobretudo, em relação à busca de confiança em si próprio e fortalecimento frente aos obstáculos.
As conquistas estão associadas a muito trabalho e dedicação, fator contributivo para obter efeitos positivos nos negócios. O trecho da entrevista traz uma breve explicação sobre essa percepção.

"Eu falo, mas tem que sustentar o que quer, tem que saber o que quer, tem que descobrir o que quer. Eu descobri, ou aprendi a ser empreendedora, não sei se aprendi ou nasci empreendedora". (CME)

Esse processo de autorreflexão resulta em certo grau de controle sobre pensamentos, sentimentos e ações, uma capacidade metacognitiva que vai fortalecer crenças sobre suas capacidades individuais de realização (Bandura et al., 2008). Bandura (1997) afirma que nenhuma referência é mais essencial do que as crenças pessoais em sua disposição de exercer uma medida de controle sobre o seu próprio comportamento. Há evidências de que as pessoas se baseiam nas crenças básicas de que é preciso ter poder para produzir efeitos por meio das próprias ações (Bandura et al., 2008). A autorreflexão aparece como característica essencial da agência humana, que abrange a capacidade metacognitiva de refletir sobre si mesmo e sobre a adequação dos próprios pensamentos e ações (Bandura et al., 2008).

A trajetória dos empreendedores apontam as ações que contribuíram para o sucesso alcançado no desenvolvimento do negócio.

"Hoje com toda essa ebulição que o país está passando, porque eu não penso que seja problema, eu vejo como processo de ebulição que vai ter que achar o equilíbrio, e isso eu tenho aprendido muito como conselheira do Sicredi, não temer na hora das crises, das dificuldades".(CME)

Os dados indicam que a capacidade de autorreflexão contribui para empreendedores superarem desafios no percurso do desenvolvimento do negócio.

Todos esses aspectos encontrados na análise dos depoimentos são explicados por McClelland (1972), pela abordagem psicológica, como traços de personalidade que são próprios a estes indivíduos.

O comportamento empreendedor, sob a perspectivadanecessidade deautorrealização(Nach), é evidenciado na trajetória dos empreendedores participantes da pesquisa convergindo com várias características empreendedoras como acreditar, ser confiante e autodeterminado, demonstrando capacidade de planejar, assumir as próprias decisões, além de ter participação ativa nos 
projetos de criação e desenvolvimento do negócio. Ao se mostrarem confiantes, autodeterminados para desenvolver ações, conseguiram identificar estratégias que os direcionassem ao alcance dos seus objetivos. A iniciativa e a determinação foram características muito presentes no comportamento dos empreendedores. O depoimento a seguir ilustra.

"Eu fui buscando fontes, fui indo nas feiras, aí as pessoas ficam conhecendo outras e aí hoje eu tenho um monte de empresas que eu conheço que me conhece, que eu já tenho crédito e sabe quem sou". (CME)

Os dados indicam que, a capacidade de iniciativa, confiança e autodeterminação que são mobilizadores para a autorrealização, verificada nas ações dos empreendedores, foram fundamentais para criação e desenvolvimento do negócio. Essas ações convergem com o pensamento de McClelland (1965) e McClelland e Rumelhart (1986) que consideram a necessidade de realização como a característica mais distintiva da motivação para a realização e introduz ainda, entre as características de necessidade de realização, a iniciativa, a afirmação e orientação para eficiência. Sob a ótica da agência humana, o indivíduo se torna agente e receptor de situações que se produzem e, ao mesmo tempo, essas situações determinam seus pensamentos, emoções e comportamentos futuros (Bandura, 1989; Martinez \& Salanova, 2006).

A autorrealização, impulsionadora das ações de iniciativa, alinhada à antecipação, permite que as pessoas transcendam os pareceres de seu meio imediato, moldem e regulem o presente para acomodá-lo em um futuro e, assim, ajustar seu comportamento visando resultados positivos (Bandura, 2008).

Desta forma, a teoria social cognitiva, na perspectiva da agência humana, explica o comportamento empreendedor em razão da presença de intencionalidade, antecipação, autorreatividade e autorreflexão presentes nas ações dos empreendedores. E, como consequência, os mesmos podem influenciar o próprio funcionamento e as conjunturas de vida de modo propositado acarretando em ações auto-organizadas, proativas, autorreguladas e autorreflexivas, cooperando para as circunstâncias de suas vidas, não sendo apenas produtos dessas condições (Bandura, 2001). Afinal, ser agente significa fazer as coisas acontecerem de maneira intencional, por meio dos próprios atos (Bandura et al., 2008).
Presença do construto do capital psicológico no comportamento empreendedor

A categoria capital psicológico que envolve a autoeficácia, otimismo, esperança e resiliência evidencia a presença de comportamentos empreendedores nos participantes da pesquisa em várias fases da criação e desenvolvimento do negócio. Inicialmente, observa-se o surgimento da ideia de empreender como um período desafiador, visto que encararam e venceram muitos desafios e obstáculos como ausência de mecanismos de formação para o negócio, instabilidade do mercado, além da alta exigência dos clientes.

\section{Autoeficácia como explicação para comportamento empreendedor}

A autoeficácia, um dos componentes do capital psicológico, e também mobilizador do comportamento empreendedor, foi fundamental no processo de desenvolvimento do negócio de vários empreendedores participantes da pesquisa. Os trechos das entrevistas indicam a presença da autoeficácia como fonte de superação dos obstáculos no processo de criação do negócio dos empreendedores entrevistados:

"Eu acredito em mim sabe por quê? Você estar por 20 anos desenvolvendo um negócio, e ele sempre em crescimento, mesmo que em percentuais anos maiores, anos menores, mas ele sempre cresceu... por isso eu falo assim: teve trabalho, teve empenho, teve perseverança, tempos difíceis, soubemos superar algumas dificuldades... do que se faturava, recuperava um valor para emergência, então você vai seguindo alguns critérios, mas você estar numa atividade há mais de 20 anos, e ela crescendo e você todo dia estar disposto a vir para ela, é por ter uma força a mais que te guia, senão você já teria abandonado" (ACIAP).

"Você tem que acreditar que os desafios que aparecem, você tem capacidade de superar... a gente vai absorvendo as dificuldades, os obstáculos, porque você atende aqui uma infinidade de clientes por dia, cada um tem o seu jeito de ser, a gente tem que pensar antes que o cliente, você tem que conhecer... as vezes o cliente chega lá na frente, e antes que as meninas perguntem, você já sabe o que ele quer, você tem que pensar rápido... você não pode ficar: mas qual o senhor vai querer? Você tem que pensar e resolver antes que ele, eu penso assim, eu acho que tem que ser 
assim, porque incomoda você ficar em frente ao cliente gaguejando" (CME).

"... Eu sou uma pessoa guerreira, eu não tenho muito medo das coisas não! Eu tento, eu vou até o fundo né... se não der certo, não deu... mas que eu tentei, eu tentei... que é para eu não me arrepender depois né, vamos lá." (CME).

Verificamos que a capacidade para mobilizar recursos cognitivos e cursos de ação é necessária para realizar com êxito uma tarefa específica num dado contexto (Bandura, 1997; Stajkovic \& Luthans, 1998).

A força que os empreendedores têm para superar os desafios é retirada da crença da autoeficácia.

Por conseguinte, em vários momentos de suas trajetórias os empreendedores tiveram que despender esforços e acreditar na sua capacidade para superar as intempéries surgidas no dia a dia do negócio. As ações relatadas vão ao encontro de pesquisas de vários autores que assinalam que, para entender características empreendedoras, a autoeficácia tem sido e continua a ser uma variável psicológica fundamental no estudo do comportamento empreendedor, com poder preditivo sobre a intenção de criar um negócio (Boyd \& Vozikis, 1994; Bygrave \& Zacharakis, 2010; Liñán \& Chen, 2009; Pihie, 2009).

Sob a visão de Bandura (1997), a autoeficácia demonstra potencial para atingir determinado nível de exigência numa tarefa, com um domínio específico. Assim, para explicar o comportamento empreendedor, a autoeficácia é definida no modelo do capital psicológico como confiança na própria capacidade de mobilizar recursos cognitivos para obter recursos específicos (Luthans \& Youssef, 2004), crenças na capacidade para organizar e executar o curso de ação necessária para produzir algo (Bandura, 1997), além de entender que pessoas autoeficazes primam por tarefas desafiadoras, estendendo motivação e esforço no cumprimento de seus objetivos principalmente quando confrontados com obstáculos (Luthans \& Youssef, 2004).

\section{Otimismo como explicação para comportamento empreendedor}

O otimismo, outro componente do capital psicológico, e também mobilizador do comportamento empreendedor, foi fundamental no processo de desenvolvimento do negócio de vários empreendedores participantes da pesquisa. Os trechos das entrevistas ilustram como este construto auxilia no comportamento empreendedor em direção ao alcance dos objetivos instituídos no processo de criação e desenvolvimento do negócio:

"O mercado quando passa por algumas dificuldades ele se fecha, então estamos passando por uma crise, mas graças a Deus nós temos os nossos clientes ... vai um, vem outro, e isso é normal em qualquer segmento" (CME).

"Se eu esperar que o futuro vai ser uma coisa negativa, vai ser uma coisa negativa... então eu espero que o melhor ainda está por vir, eu espero não! Eu acredito nisso, eu sempre acreditei nisso ... mas para o futuro eu acredito que a gente tenha capacidade de avançar um pouquinho mais ainda ... então eu acredito que para o futuro tem uma perspectiva ainda muito boa de crescimento nos dois setores" (ACIAP).

"Quanto à crise ... eu sou muito otimista quanto a isso, eu sou muito de trocar a palavra 'crise', tirar o 's' e transformar em 'crie'... eu penso que reclamar não resolve problemas, então vamos buscar estratégias para melhorar, pega os estoques que estão velhos e faz uma promoção, faz girar ..." (CME).

O otimismo faz com que os empreendedores sejam perseverantes frente aos obstáculos, revigorando seus pensamentos frente às objeções, além de ser uma referência para a motivação. Dessa maneira, foi possível observar que os empreendedores confiam na sua capacidade de superar as contrariedades surgidas no dia a dia do negócio, baseando suas ações no construto do PsyCap.

Segundo Luthans e Church (2002) e Seligman (2005), o otimismo é conceito base do capital psicológico positivo e, portanto, uma âncora para explicar o comportamento empreendedor. Lopes, Cunha e Palma (2005) confirmam que estes aspectos convergem com uma crença generalizada que coisas boas acontecem no futuro.

\section{Esperança como explicação para comportamento empreendedor}

Se coisas boas acontecem no futuro, vemos que o construto otimismo está relacionado com outro componente do PsyCap, a esperança.

Os depoimentos a seguir resumem como a esperança direciona o empreendedor em direção ao alcance das metas e objetivos estabelecidos. 
"Então a gente viu um caminho, abriu uma oportunidade, a gente já tinha os amigos, já tinha os conhecidos, já sabia para quem ele vendia o seguro, porque ele já estava há mais de dez anos, então ele conhecia muito o ramo, conhecia muita gente" (CME).

"Então a gente tem tantos planos, daí eu penso assim: quem não sonha também já está morto? Você tem que sonhar sim, mas para ser sincero eu quero organizar muita coisa aqui mesmo, para depois pensar, por exemplo em uma segunda loja, e aí por diante, ou seja, montar uma loja em outra cidade ... outro sonho é o e-commerce, a gente sabe que isso é uma tendência, o faturamento aumenta ano a ano, milhões e milhões, não tem crise nesse setor, o comércio eletrônico vem crescendo, então eu também tenho esse sonho de partir para o comércio eletrônico, mas sei que tem um grau de dificuldade muito grande, é muito sério você partir para isso, não pode ser amador... mas a princípio os dois sonhos são esses" (ACIAP).

"Nos desafios e nas dificuldades que eu passei, eu nunca lamentei, eu te digo que eu sempre aprendi alguma coisa nas situações, seja ela boa ou ruim. Eu sempre, sempre tive assim um equilíbrio nas minhas dificuldades, talvez porque eu sempre tive um apoio muito forte, então eu sempre digo, acredite que você pode, nunca achei nada difícil, então quando você acredita em você, as dificuldades ficam mais leves" (CME).

Em vários momentos foi possível verificar o estabelecimento de estratégias para o negócio alinhadas à esperança, uma disposição ativa e otimista pautada por entusiasmo e competência de alocar subsídios positivos na conquista de objetivos com coragem. Ter esperança é confiar que é possível instituir objetivos, descobrir um modo de conseguilos e motivar-se para alcançá-los (Snyder, 2002).

\section{Resiliência como explicação comportamento empreendedor}

A resiliência, outro componente do PsyCap, foi essencial no processo de desenvolvimento do negócio de vários empreendedores participantes da pesquisa.

“Eu era professora e empresária ao mesmo tempo, então a diferença, a pressão era muito grande na minha cabeça, eu tinha que rodar um giro de 360 graus, porque eu tinha que estar numa sala de aula e depois estar ali no armazém" (CME).

"Nós tivemos momentos conturbados, mas a gente conseguiu passar por isso de forma muito serena, não muito tranquila, mas sobrevivemos a tudo isso... e eu vou te dizer uma coisa! Sabe que já estou até gostando do tal do desafio, porque nós já passamos por tantas coisas. Eu nasci praticamente dentro do desafio, dentro do obstáculo. ... Então a gente sobreviveu, passou por aquele momento, como todo setor, como todo ramo tem, mas foi uma experiência, e está sendo uma experiência assim exitosa, onde a gente só tem a agradecer" (ACIAP).

"Por isso eu falo assim, teve trabalho, teve empenho, teve perseverança, tempos difíceis... soubemos superar algumas dificuldades... mas você estar numa atividade há mais de 20 anos, e ela sempre crescendo, e você todo dia estar com vontade de vir para ela, eu acredito que eu tenho uma força, um diferencial, senão eu já teria abandonado" (ACIAP).

"Eu enfrentei na minha vida muitos desafios, e nós temos que saber enfrentar nossos limites. Então eu acho que em tudo isso tem que haver um amadurecimento, porque primeiro a gente tem que ser pra depois ter, e o ser e o ter tem que ter equilíbrio. Nos desafios e dificuldades que eu passei, eu nunca lamentei, eu te digo que sempre eu aprendi alguma coisa nas situações, seja ela boa ou ruim. Eu sempre tive um equilíbrio nas minhas dificuldades, talvez porque eu sempre tive um apoio muito forte" (CME).

Os dados indicam que a resiliência faz com que os empreendedores estabeleçam caminhos para superar as adversidades por acreditarem que são fortes e conseguem ultrapassar esses entraves. Em vários momentos das entrevistas foi possível verificar comportamentos de superação por meio do estabelecimento de ações alinhadas aos propósitos dos empreendimentos. As performances relatadas convergem com pesquisas no campo do PsyCap, que também encontraram em empreendedores a característica de resiliência (Luthans, Youssef, \& Avolio, 2007; Nassif, Leão, \& Garçon, 2018).

Assim, o estabelecimento de táticas a partir da crença na sua capacidade de superar situações que culminassem no sucesso do negócio fez toda diferença nos negócios dos entrevistados. Sob o olhar da psicologia, há várias formas de explicar a superação de crises e adversidades enfrentadas pelas pessoas, grupos e organizações (Schwarzer 
\& Knoll, 2003). Dentre elas, a resiliência, pois os indivíduos resilientes são portadores da capacidade de recuperação/superação da adversidade, incerteza, falha, e até mesmo da mudança positiva com tarefas que acarretam maior responsabilidade (Luthans, 2002; Luthans \& Youssef, 2004).

O PsyCap, portanto, constitui um campo adequado para o entendimento do comportamento empreendedor a partir dos seus elementos: autoeficácia, otimismo, esperança e resiliência presentes nas ações dos empreendedores.

A teoria social cognitiva, ao apontar a agência humana como sua base de referência e subsidiar na eficácia do indivíduo, se aproxima do capital psicológico que nomeia quatro capacidades psicológicas para formar seu construto cuja autoeficácia se funde ao otimismo, a esperança e a resiliência, tornando, assim, um construto unifatorial. Imbricado a estes dois construtos, evidenciamos as características do comportamento empreendedor que, sob a alusão da autorrealização, estão pautadas na iniciativa, na afirmação, na orientação para eficiência, no planejamento sistemático e no comprometimento com o trabalho. Por sua vez, a autorrealização é uma das características psicológicas que fornece condições às pessoas de escolherem e persistirem em atividades que envolvem um padrão de excelência e/ou em tarefas desafiadoras.

\section{CONSIDERAÇÕES FINAIS}

Esse estudo foi desenvolvido com o propósito de contribuir para a ampliação do conhecimento no âmbito do comportamento empreendedor a partir de duas teorias da Psicologia Positiva. Os resultados evidenciam que as ações desenvolvidas em três grupos de diferentes perfis de empreendedores diretores da ACIAP, mulheres do CME e jovens do COJEP - no decorrer da criação e desenvolvimento do negócio estão alinhadas às características empreendedoras conforme a literatura, sem distinção de gênero ou idade.

As experiências dos respondentes ilustram e corroboraram os comportamentos de agência humana, na iniciativa e na capacidade de superação de obstáculos. Todos confessaram que aprenderam a lidar com as adversidades como um mecanismo de autorrealização. As ações de iniciativas ficaram claras nos processos de identificação de oportunidades e ameaças aos negócios.

Partindo da referência das capacidades psicológicas que prediz quem somos e em quem podemos nos tornar, foi possível identificar nesses grupos a autoeficácia, otimismo, esperança e resiliência. Esses comportamentos emergem em situações de tomada de decisão em ambiente altamente inseguro, de alto risco e intensa pressão de tempo, ou seja, um cenário de considerável investimento emocional.

Reforça-se, assim, os pressupostos teóricos sobre o PsyCap: ele, de fato, contribui para o entendimento de comportamento empreendedor no processo de criação e desenvolvimento do negócio, principalmente, em relação aos fatores que levam à longevidade do empreendimento.

Também, confirmou-se que os componentes Esperança e Otimismo são mecanismos para o enfrentamento de desafios e a autoeficácia auxilia na criação de estratégias e ações que conduzem ao sucesso do negócio. Destaca-se a resiliência, uma capacidade que os empreendedores entrevistados demonstraram como elemento de superação às dificuldades.

Um achado dessa pesquisa é o sentimento de solidariedade. Ele emergiu das falas dos entrevistados de maneira espontânea, como um comportamento voltado à retribuição à sociedade dos resultados de suas conquistas individuais. Essa descoberta indica que a solidariedade possa ser um construto passível de investigações futuras.

Por se tratar de construtos unifatoriais, a eleição por importância dos atributos do comportamento empreendedor não se faz adequada. Assim, fica clara e caracterizada que os construtos do capital psicológico e da agência humana podem ser entendidos como uma importante forma de analisar, compreender e entender o comportamento empreendedor.

Esses achados indicam que as forças psicológicas atuam como elementos fundamentais e de extrema importância para o sucesso do empreendedor, tendo que ser compreendidas no âmbito teórico e gerencial como um elemento de relevância às pesquisas.

A agência humana, base da teoria social cognitiva, orienta a busca da compreensão do êxito, bem como do fracasso de um empreendimento a partir do envolvimento substancial do empreendedor, porque ele é o centralizador das decisões e o estrategista, ainda que tenha colaboração e suporte de outras pessoas no processo de gestão do negócio.

Visto o capital psicológico ser também um construto de grande relevância para estudar o comportamento empreendedor, sugere-se que o mesmo possa ser incrementado em programas de empreendedorismo, fazendo despertar potencialidades que poderão trabalhar a favor do crescimento e desenvolvimento dos negócios, contribuindo desta maneira com seu processo empreendedor. Como identificado nos achados 
da pesquisa, há evidências que o PsyCap pode ser aprimorado e, assim, criar uma agência humana cujos indivíduos possam desenvolver comportamento empreendedor que os auxiliem na superação de obstáculos e adversidades, levando-os à produtividade e sucesso nos negócios.

As contribuições trazidas pelos resultados da pesquisa são relevantes para a ampliação da área de conhecimento. No entanto, para que os resultados

\section{REFERÊNCIAS}

Almeida, F. M., Valadares, J. L., \& Sediyama, G. A. S. (2017). A contribuição do empreendedorismo para o crescimento econômico dos estados brasileiros. Revista de Empreendedorismo e Gestão de Pequenas Empresas, 6(3), 466-494. http://dx.doi.org/10.14211/regepe.v6i3.552

Amorim, R. C. Neto, Rodrigues, V. P., Stewart, D., Xiao, A., \& Snyder, J. (2018). The influence of self-efficacy on entrepreneurial behavior among K-12 teachers. Teaching and Teacher Education, 72, 44-53. https://doi. org/10.1016/j.tate.2018.02.012

Armond, A. C., \& Nassif, V. M. J. (2009). A liderança como elemento do comportamento empreendedor: Um estudo exploratório. RAM. Revista de Administração Mackenzie, 10(5), 77-106. https://dx.doi.org/10.1590/S167869712009000500005

Bandura, A. (1977). Social learning theory. Englewood Cliffs, N.J.: Prentice-Hall.

Bandura, A. (1986). Social foundations of thought and action: A social cognitive theory. Englewood Cliffs, N.J.: PrenticeHall.

Bandura, A. (1989). Human agency in social cognitive theory. American Psychologist, 44(9), 1175-1184. https://dx.doi. org/10.1037/0003-066x.44.9.1175

Bandura, A. (1991). Self-regulation of motivation through anticipatory and self-regulatory mechanisms. In R. A. Dienstbier (Ed.), Nebraska symposium on motivation: Perspectives on motivation (Vol. 38, pp. 69-164). Lincoln: University of Nebraska Press.

Bandura, A. (1993). Perceived self-efficacy in cognitive development and functioning. Educational Psychologist, 28, 117-148. https://doi.org/10.1207/ s15326985ep2802_3

Bandura, A. (1997). Self-efficacy: The exercise of control. New York: Freeman.

Bandura, A. (2001). Social cognitive theory: An agentic perspective. Annual Review of Psychology, 52, 1-26. https://doi. org/10.1146/annurev.psych.52.1.1 sejam confirmados e generalizados, há necessidade de estudos em diferentes contextos e grupos, além de investigar os atributos por meio de outros métodos e tipos de pesquisa. Assim, sugerimos que os resultados sejam fontes de novas investigações, com a possibilidade de construir modelos confirmatórios do comportamento empreendedor, integrando, conjuntamente, os atributos das duas teorias da psicologia positiva investigadas.

Bandura, A. (2008). A evolução da teoria social cognitiva. In: A. Bandura, R. G. Azzi, S. A. J. Polydoro, (Orgs.), Teoria social cognitiva: Conceitos básicos (pp. 15-41). Porto Alegre: Artmed

Bandura, A., Azzi, R. G., \& Polydoro, S. A. J. (2008). Teoria social cognitiva: Conceitos básicos. Porto Alegre: Artmed.

Bardin, L. (1977). Análise de conteúdo. Lisboa: Edições 70.

Baron, R. A., \& Shane, S. A. (2011). Empreendedorismo: Uma visão do processo. São Paulo: Cengage Learning.

Bernardino, S., Santos, J. F., \& Cardoso, C. (2018). Empreender no feminino em Portugal: Motivações e obstáculos. European Journal of Applied Business Management, 4(1), 101-117. Retrieved from http://nidisag.isag.pt/index. php/IJAM/article/view/290

Bhidé, A. (2004). Como os empreendedores constroem estratégias que dão certo. In: Empreendedorismo e estratégia. Rio de Janeiro: Campus.

Boyd, N. G., \& Vozikis, G. S. (1994). The influence of self-efficacy on the development of entrepreneurial intentions and actions. Entrepreneurship Theory \& Practice, 18(4), 6377. https://doi.org/10.1177/104225879401800404

Brancher, I. B., Oliveira, E. M., \& Roncon, A. (2012) Comportamento empreendedor: Estudo bibliométrico da produção nacional e a influência de referencial teórico internacional. Internext - Revista Eletrônica de Negócios Internacionais, 7(1), 166-193. http://dx.doi. org/10.18568/1980-4865.71166-193

Brockhaus, R. H. (1982). Psychology of the entrepreneur. In C. A. Kent, D. L. Sexton \& K. H. Vesper (Eds.), Encyclopedia of Entrepreneurship (pp. 39-71). Englewood Cliffs, NJ: Prentice-Hall.

Brockhaus, R. H., \& Horwitz, P. S. (1986). The psychology of the entrepreneur. In D. L. Sexton \& R. W. Smilor (Eds.), The art and science of entrepreneurship (pp. 25-48). Cambridge, MA: Ballinger. 
Brush, C. G., Carter, N., Greene, P. G., Hart, M., \& Gatewood, E. J. (2002). The role of social capital and gender in linking financial suppliers and entrepreneurial firms: A framework for future research. Venture Capital, 4(4), 305323. https://doi.org/10.1080/1369106022000024897

Bruyat, C., \& Julien, P.-A. (2001) Defining the field of research in entrepreneurship. Journal of Business Venturing, 16(2), 165-180. https://doi.org/10.1016/S08839026(99)00043-9

Bullough, A., Renko, M., \& Myatt, T. (2014). Danger zone entrepreneurs: The importance of resilience and selfefficacy for entrepreneurial intentions. Entrepreneurship Theory and Practice, 38(3), 473-499. https://doi. org/10.1111/etap.12006

Bygrave, W. D., \& Zacharakis, A. (2010). The entrepreneurial process. The Portable MBA in Entrepreneurship (Chapter 1), (4th ed.). Hoboken, N. J.: John Wiley \& Sons, Inc.

Bygrave, W. D., \& Hofer, C. W. (1991). Theorizing about entrepreneurship. Entrepreneurship Theory \& Practice, 16(2), 13-22. https://doi. org/10.1177/104225879201600203

Csikszentmihalyi, M. (2004). What we must accomplish in the coming decades. Zygon, 39(2), 359-366. https://doi. org/10.1111/j.1467-9744.2004.00579.x

Dai, N., Ivanov, V., \& Cole, R. A. (2017). Entrepreneurial optimism, credit availability, and cost of financing: evidence from U.S. small businesses. Journal of Corporate Finance, 44, 289-307. https://doi.org/10.1016/j. jcorpfin.2017.04.005

Damasio, A. R. (1995). Review: Toward a neurobiology of emotion and feeling: operational concepts and hypotheses. The Neuroscientist, 1(1), 19-25. https://doi. org/10.1177/107385849500100104

Envick, B. R. (2014). Achieving entrepreneurial success through passion, vision \& courage: A cognitive model for developing entrepreneurial intelligence. Academy of Entrepreneurship Journal, 20(1), 55-74. Retrieved from https://www.researchgate.net/publication/286214326_ Achieiving_entrepreneurial_success_through_passion_ vision_courage_A_cognitive_model_for_developing_ entrepreneurial_intelligence

Filion, L. J. (1999). Empreendedorismo: Empreendedores e proprietários-gerentes de pequenos negócios. Revista de Administração, 34(2), 6-28. Retrieved from http://www.spell.org.br/documentos/ver/18122/ empreendedorismo--empreendedores-e-proprietariosgerentes-de-pequenos-negocios/i/pt-br

Flick, U. (2009). Qualidade na pesquisa qualitativa. Porto Alegre: Artmed.

Flores, J. G. (1994). Análisis de datos cualitativos: Aplicaciones a la investigación educativa. Barcelona: PPU.

Fourati, H., \& Attitalah, R. B. (2018). Entrepreneurial optimism, the nature of entrepreneurial experience and debt decision for business start-up. International Journal of Innovation Management, 22(3), 1-26. https://doi. org/10.1142/S136391961850024X
Giacomin, O, Janssen, F., \& Shinnar, R. S. (2015). University students and their faculty: Perceptions of entrepreneurial optimism, overconfidence and entrepreneurial intentions. Management International, 20(1), 123-134. https://doi.org/10.7202/1045360ar

Gong, Y., Huang, J., \& Farh, J. (2009). Employee learning orientation, transformational leadership, and employee creativity: The mediating role of creative self-efficacy. Academy of Management Journal, 52(4), 765-778. https://doi.org/10.5465/amj.2009.43670890

Guimarães, E. H. Jr. (2019). Como os empreendedores trabalham: Uma leitura psicodinâmica da organização do trabalho de um grupo de empreendedores. Revista de Empreendedorismo e Gestão de Pequenas Empresas, 8(1), 149-175. http://dx.doi.org/10.14211/regepe.v8i1.889

Honma, E. T. (2007). Competências empreendedoras: Estudo de casos múltiplos no setor hoteleiro em Curitiba (Dissertação de Mestrado). Universidade Federal do Paraná, Curitiba, PR, Brasil. Retrieved from http://hdl. handle.net/1884/8108

Jiang, W., \& Gu, Q. (2017). Leader creativity expectations motivate employee creativity: A moderated mediation examination. The International Journal of Human Resource Management, 28(5), 724-749. https://doi.org/ $10.1080 / 09585192.2015 .1109535$

Julien, P. A. (2010). Empreendedorismo regional e a economia do conhecimento. São Paulo: Saraiva.

Kirzner, I. M. (1973). Competition and entrepreneurship. Chicago: Chicago University Press.

Kirzner, I. M. (2009). The alert and creative entrepreneur: A clarification. Small Business Economics, 32(2), 145-152. https://doi.org/10.1007/s11187-008-9153-7

Kuratko, D. F., Ireland, R. D., Covin, J. G., \& Hornsby, J. S. (2005) A model of middle-level managers' entrepreneurial behavior. Entrepreneurship Theory and Practice, 29(6), 699-716. https://doi.org/10.1111/j.1540$6520.2005 .00104 . x$

Langdridge, D. (2007). Phenomenological psychology: Theory, research and method. Harlow, England: Pearson Prentice Hall.

Lazarus, R. S. (1991). Cognition and motivation in emotion. American Psychologist, 46(4), 352-367. https://doi. org/10.1037/0003-066X.46.4.352

Lazarus, R. S., \& Folkman, S. (1994). Stress, appraisal, and coping. New York: Springer Publishing Company.

Lévesque, M., \& Minniti, M. (2006). The effect of aging on entrepreneurial behavior. Journal of Business Venturing, 21(2), 177-194. https://doi.org/10.1016/j. jbusvent.2005.04.003

Lima, L. G., \& Nassif, V. M. J. (2017a). Capital psicológico e comportamento empreendedor sob uma análise da trajetória de mulheres empreendedoras. Revista Livre de Sustentabilidade e Empreendedorismo, 2(1), 183-206. Retrieved from http://www.relise.eco.br/index.php/ relise/article/view/61 
Lima, L. G., \& Nassif, V. M. J. (2017b). Similitudes entre teoria social cognitiva, capital psicológico. Gestão e Planejamento, 18, 369-385. https://doi.org/10.21714/2178-8030gep. v18.4517

Liñán, F., \& Chen, Y. W. (2009). Development and cross-cultural application of a specific instrument to measure entrepreneurial intentions. Entrepreneurship Theory and Practice, 33(3), 593-617. https://doi.org/10.1111/ j.1540-6520.2009.00318.x

Lopes, M. P., Cunha, M. P.\& Palma, P. J. (2006). Positive psychological capital: Distinguishing profiles and their impact on organizational climate. Working Paper ISPA, OB 02/2006. Retrieved from http://www.ispa.pt/NR/rdonlyres/ C31506FF-B1AA-4E7E-8B7D-BE2A6D4797BB/176/WP_ ISPA_OB032006.pdf

Luthans, F. (2002). The need for and meaning of positive organizational behavior. Journal of Organizational Behavior, 23(6), 695-706. https://doi.org/10.1002/ job. 165

Luthans, F, Church, A. H. (2002). Positive organizational behavior: Developing and managing psychological strengths. Academy of Management Executive, 16(1), 57-75. Retrieved from https://www.jstor.org/stable/4165814

Luthans, F., \& Youssef, C. M. (2004). Human, social, and now positive psychological capital management: Investing in people for competitive advantage. Organizational Dynamics, 33(2), 143-160. https://doi.org/10.1016/j. orgdyn.2004.01.003

Luthans, F., Youssef, C., \& Avolio, B. (2007). Psychological capital: Developing the human competitive edge. New York: Oxford University Press.

Manen, M. van (1990). Researching lived experience: Human science for an action sensitive pedagogy. New York: State University of New York Press.

Martínez, I. M., \& Salanova, M. (2006). Autoeficacia en el trabajo: El poder de creer que tú puedes. Estudios financieros, 45, 175-202. Retrieved from http://www.want.uji.es/ download/autoeficacia-en-el-trabajo-el-poder-de-creerque-tu-puedes/

McClelland, D. C. (1961). The achieving society, Princeton, NJ: Van Norstrand Co. Inc.

McClelland, D. C. (1962). Business drive and national achievement. Harvard Business Review, July-August, 103-105.

McClelland, D. C. (1965). N Achievement and entrepreneurship: A longitudinal study. Journal of Personality and Social Psychology, 1(4), 389-392. https://doi.org/10.1037/ h0021956

McClelland, J. L., \& Rumelhart, D. E. (1986). Parallel distributed processing. explorations in the microstructure of cognition. Cambridge, MA: MIT Press.

Mehrabi, R., \& Kolabi, A. M. (2012). Investigating effect of entrepreneur's personal attributes and cognitive heuristics on the quality of entrepreneurial strategic decision making. Global Business and Management Research: An International Journal, 4(2), 178-192.
Nassif, V. M. J., Hashimoto, M., \& Amaral, D. J. (2014). Entrepreneurs' self-perception of planning skills: evidences from Brazilian entrepreneurs. Revista IberoAmericana de Estratégia, 13(4), 107-121. https://doi. org/10.5585/riae.v13i4.2060

Nassif, V. M., Leão, A. C., \& Garçon, M. M. (2018, november). O afetivo e o cognitivo de mãos dadas: Uma avaliação das ameaças e comportamentos de superação no empreendedorismo por mulheres. Anais do Seminários de Administração - SemeAD, São Paulo, SP, Brasil, 21.

Page, L. F., \& Donohue, R. (2004). Positive psychological capital: A preliminary exploration of the construct [Working Paper 51/04]. Monash University, Business and Economics, Melbourne, Australia.

Pihie, Z. A. L. (2009). Entrepreneurship as a career choice: An analysis of entrepreneurial self-efficacy and intention of university students. European Journal of Social Science, 9(2), 338-349. Retrieved from https://www.researchgate. net/publication/289748113_Entrepreneurship_as_a_ career_choice_An_analysis_of_entrepreneurial_selfefficacy_and_intention_of_university_students

Richter, A. W., Hirst, G., Knippenberg, D. van, \& Baer, M. (2012). Creative self-efficacy and individual creativity in team contexts: Cross-level interactions with team informational resources. Journal of Applied Psychology, 97(6),1282-1290. https://doi.org/10.1037/a0029359

Schaefer, R., \& Minello, I. F. (2017). Mentalidade empreendedora: O modo de pensar do indivíduo empreendedor. Revista de Empreendedorismo e Gestão de Pequenas Empresas, 6(3), 495-524. http://dx.doi.org/10.14211/regepe.v6i3.422.

Scheier, M. F., \& Carver, C. S. (2003). Optimism. In S. J. Lopez. \& C. R. Snyder (Eds.), Positive Psychological Assessment: A handbook of models and measures (pp. 75-89). Washington DC: American Psychological Association.

Schwarzer, R., \& Knoll, N. (2003). Positive coping: Mastering demands and searching for meaning. In S. J. Lopez \& C. R. Snyder (Eds.), Positive Psychological assessment: A handbook of models and measures (pp. 393-409). Washington, DC: American Psychological Association.

Seligman, M. E. P. (2005). Positive psychology, positive prevention, and positive therapy. In S. J. Lopez \& C. R. Snyder (Eds.), Handbook of positive psychology. Oxford: Oxford University Press.

Shane, S., \& Venkataraman, S. (2000). The promise of entrepreneurship as a field of research. Academy of Management Review. 25(1), 217-226. https://doi. org/10.5465/amr.2000.2791611

Smith, K. G., Di Gregorio, D., \& Anderson, R. O. (2002). Bisociation, discovery and the role of entrepreneurial action. In M. A. Hitt, R. D. Ireland, S. M. Camp \& D. Sexton (Eds.), Strategic entrepreneurship: Creating a new mindset (pp. 127-150). New York: Wiley-Blackwell

Snyder, C.R. (2002). Hope theory: Rainbows in the mind. Psychological Inquiry, 13(4), 249-275. https://doi. org/10.1207/S15327965PLI1304_01

Stajkovic, A., \& Luthans, F. (1998). Self-efficacy and work-related performance: A meta-analysis. Psychological Bulletin, 124(2), 240-261. https://doi.org/10.1037/0033 2909.124.2.240 
Tierney, P., \& Farmer, S. M. (2011). Creative self-efficacy development and creative performance over time. Journal of Applied Psychology, 96(2), 277-293. https:// doi.org/10.1037/a0020952

Urban, B. (2012). The venture creation process, entrepreneurial self-efficacy and competitiveness: A focus on technology enterprises. Journal of Strategic Innovation and Sustainability, 7(3), 66-83. Retrieved from https:// www.semanticscholar.org/paper/The-Venture-CreationProcess\%2C-Entrepreneurial-and-Urban/9566063458d0 14e597830a1c362929429a324c62\#paper-header

\section{Autores}

\section{Luciano Gonçalves de Lima*}

Rua Deputado Salvador Julianelli, s/n, Barra Funda, 05001900, São Paulo, SP, Brasil

E-mail: lucyano_lima@yahoo.com.br

난 https://orcid.org/0000-0003-3426-8235

\section{Vânia Maria Jorge Nassif}

Rua Deputado Salvador Julianelli, s/n, Barra Funda, 05001900, São Paulo, SP, Brasil

E-mail: vania.nassif@gmail.com

• https://orcid.org/0000-0003-3601-2831

\section{Marcia Maria Garçon}

Rua Deputado Salvador Julianelli, s/n, Barra Funda, 05001900, São Paulo, SP, Brasil

E-mail: mgarcon@gmail.com

- https://orcid.org/0000-0002-4077-8154

* Autor Correspondente

\section{Método de Revisão por Pares}

Este conteúdo foi avaliado utilizando o processo de revisão por pares duplo-cego (double-blind peer-review). A divulgação das informações dos pareceristas constantes na primeira página é feita somente após a conclusão do processo avaliativo, e com o consentimento voluntário dos respectivos pareceristas.
Welter, F., Smallbone, D. (2011). Institutional perspectives on entrepreneurial behaviour in challenging environments. Journal of Small Business Management, 49(1), 107-125. https://doi.org/10.1111/j.1540-627X.2010.00317.x

Wood, M. S., Williams, D. W., \& Drover, W. (2017). Past as prologue: Entrepreneurial inaction decisions and subsequent action judgments. Journal of Business Venturing, 32(1), 107127. https://doi.org/10.1016/j.jbusvent.2016.10.008

\section{Contribuições dos Autores}

$1^{\circ}$ autor: É responsável pela elaboração de todas as etapas de construção do artigo, elaboração do projeto, revisão bibliográfica, definição da metodologia, coleta e tratamento dos dados, discussão dos resultados e conclusão.

$\mathbf{2}^{\mathbf{a}}$ autora: Orientadora da tese que deu origem ao artigo, responsável pelas orientações elaboração do texto e correções de todas as etapas realizadas pelo $1^{\circ}$ autor.

$3^{\mathbf{a}}$ autora: Colaborou na revisão bibliográfica, atualização de autores, elaboração do texto e na redação.

\section{Financiamento}

Os autores informaram que não houve apoio financeiro para a pesquisa neste artigo.

\section{Conflito de Interesses}

Os autores informaram que não há conflito de interesses.

\section{Direitos Autorais}

A RAC detém os direitos autorais deste conteúdo.

\section{Verificação de Plágio}

A RAC mantém a prática de submeter todos os documentos aprovados para publicação à verificação de plágio, mediante o emprego de ferramentas específicas, e.g.: iThenticate. 